\title{
IN-SPACE CRYOGENIC PROPELLANT DEPOT (ISCPD) ARCHITECTURE DEFINITIONS AND SYSTEMS STUDIES
}

\author{
Mr. John Fikes \\ National Aeronautics and Space Administration (NASA)/Marshall Space Flight Center, \\ Huntsville, Alabama, United States, john.fikes@nasa.gov \\ Mr. Joe T. Howell \\ National Aeronautics and Space Administration (NASA)/Marshall Space Flight Center, \\ Huntsville, Alabama, United States, joe.howell@nasa.gov \\ Mr. Mark Henley \\ The Boeing Company, Canoga Park, California, United States, \\ mark.w.henley@boeing.com
}

\begin{abstract}
The objectives of the ISCPD Architecture Definitions and Systems Studies were to determine high leverage propellant depot architecture concepts, system configuration trades, and related technologies to enable more ambitious and affordable human and robotic exploration of the Earth Neighborhood and beyond. This activity identified architectures and concepts that preposition and store propellants in space for exploration and commercial space activities, consistent with Exploration Systems Research and Technology (ESR\&T) objectives. Commonalities across mission scenarios for these architecture definitions, depot concepts, technologies, and operations were identified that also best satisfy the Vision of Space Exploration. Trade studies were conducted, technology development needs identified and assessments performed to drive out the roadmap for obtaining an in-space cryogenic propellant depot capability.

The Boeing Company supported the NASA Marshall Space Flight Center (MSFC) by conducting this Depot System Architecture Development Study. The primary objectives of this depot architecture study were: (1) determine high leverage propellant depot concepts and related technologies; (2) identify commonalities across mission scenarios of depot concepts, technologies, and operations; (3) determine the best depot concepts and key technology requirements and (4) identify technology development needs including definition of ground and space test article requirements.
\end{abstract}




\section{INTRODUCTION AND BACKGROUND}

An in-space cryogenic propellant depot capability represents a key element of NASA's visions. The servicing of propellants and consumables in space enables a multitude of mission scenarios, otherwise unavailable due to costs or operational constraints and/or inefficiencies. Cryogenic Fluid Management (CFM) technology applications are particularly suited in evolving capabilities for commercialization and solar system science missions. These applications cut across all human exploration missions, including depots, orbital transfer vehicles such as the Crew Exploration Vehicle (CEV) and other inspace stages.

At the core of the depot capability is the economic management of cryogens without undue or complicated impositions on infrastructure, other systems, or mission operations. This technology leads to autonomous fluid management operations without the complications of propellant settling and without extravehicular activity (EVA) support. The basic goal is to enable automated zero-g storage and transfer of cryogenic fluids from supply tanks (Figure 1) to user tanks: safely, reliably, and with minimum loss of propellant.

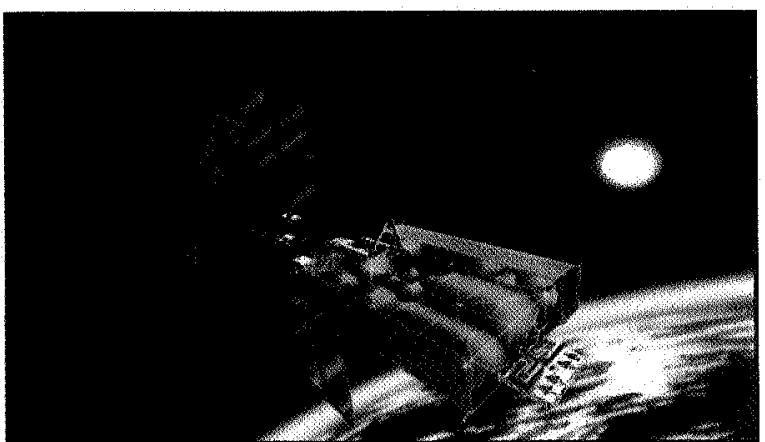

Figure 1. In-Space Cryogenic Propellant Depot Artist Concept.

\section{ARCHITECTURE DEFINITIONS}

Recommendations for ISCPD Architectures were developed based on prior studies and NASA's concurrent Exploration Systems Architecture Study (ESAS). ESAS recommended use of cryogenic hydrogen and oxygen on two upper stages for Shuttlederived launch vehicles as well as a lunar Lander. While the final architecture may vary, these are good candidate vehicles for ISCPD refueling, and Table 1 summarizes their expected quantities of cryogenic propellant. In addition, ESAS recommended use of cryogenic methane and oxygen on an Ascent Stage, including storage of these cryogens for at least two weeks in space. ESAS did not specifically require use of an ISCPD, but the NASA Administrator recommended commercial ISCPD development, with a market value of 2.5 billion dollars per year to refuel the ESAS Earth Departure Stage (EDS), thereby increasing lunar payload mass, and providing even greater value for Mars exploration.

Table 1. Cryogenic ESAS vehicles could refuel or offload residuals at an ISCPD.

\begin{tabular}{|c|c|c|c|}
\hline $\begin{array}{l}\text { Approximate } \\
\text { mass derived from } \\
\text { ESAS report in } \\
\text { metric tonnes }\end{array}$ & $\begin{array}{l}\text { Earth } \\
\text { Departure } \\
\text { Stage }\end{array}$ & $\begin{array}{l}\text { CEV } \\
\text { Cryo } \\
\text { Upper } \\
\text { Stage } \\
\end{array}$ & $\begin{array}{l}\text { Lunar } \\
\text { Lander }\end{array}$ \\
\hline Dry Mass: & 19 & 17 & \\
\hline Propellant & 208 & 164 & 25 \\
\hline Residual Fluids & 2.8 & 2.9 & 0.5 \\
\hline
\end{tabular}

Such vehicles may be refueled at a depot or deliver residual propellants (to re-fill depot tanks) and might even store cryogenic propellant in space. Figure 2 illustrates these vehicles in the recommended ESAS scenario and how they may fit ISCPD applications. 


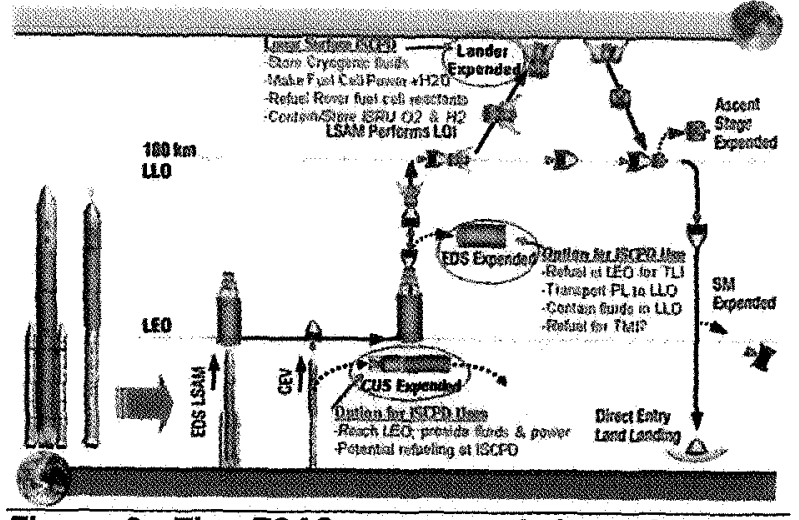

Figure 2. The ESAS-recommended architecture offers opportunities for ISCPD uses.

In the ESAS-recommended lunar architecture, the EDS would use roughly $123,000 \mathrm{~kg}$ of cryogenic propellants to reach Low Earth Orbit (LEO) where it would mate with the CEV and burn its remaining propellant $(\sim 85,000 \mathrm{~kg})$ for Trans-Lunar Injection (TLI). If the EDS were refueled in LEO as Dr. Griffin suggested, it could more than double the payload to TLI. A refueled EDS could also potentially carry payload into lunar orbit (or initiate Lander descent). Such scenarios could double or triple the payload mass to the lunar surface.

The Cryogenic Upper Stage for CEV launches is planned for suborbital flight, with re-entry over the Pacific Ocean, but it may also be able to reach orbit carrying the CEV. In orbit, the remaining tons of cryogenic propellants could provide low thrust propulsion, fuel cell power, and Environmental Control and Life Support System (ECLSS) consumables to support the CEV. If this upper stage is carried to orbit, it could off-load residual propellants at an ISCPD, or be refueled and re-used.

The lunar Lander will be designed for longer-term storage and management of cryogenic fluids: roughly one week for propulsive maneuvers and two weeks for fuel cell reactants. The Lander's cryogenic propellant storage system must withstand daytime lunar surface heating, and the Lander design includes radiators for heat rejection. Fuel cells on the Lander provide power generation from Earth launch until lunar ascent, with oxygen reactant stored in the oxygen propellant tanks, while hydrogen reactant is stored in the hydrogen propellant tanks. In this way, the Lander serves as an ISCPD and it could continue to store cryogens after the humans return to Earth, supplying reactants to refuel rovers using fuel cell power, and receiving and storing oxygen and hydrogen produced from resources found on the lunar surface (in lunar regolith and/or polar ice).

Oxygen and hydrogen production from water has the potential to provide great benefits for Space Exploration. Water may be launched from Earth at low cost or found on Earth's moon, and the moons and surface of Mars. Water electrolysis systems have been developed for the International Space Station (ISS) and one was launched on the last Space Shuttle mission, to produce gaseous oxygen (for breathing) and hydrogen (vented overboard). With refrigeration and heat exchange, we can convert such gases into cryogenic liquids, and store them at In-Space Cryogenic Propellant Depots.

The exploration architecture is expected to grow in capabilities over time. Initially, ISCPD cryogenic propellant may be delivered from Earth, using chemical propulsion to reach a depot in LEO. Launch systems may deliver cryogenic propellants in dedicated launches as well as by scavenging of residual and reserve propellants from cryogenic upper stages. Initial ISCPD capabilities may be limited to passive storage (with no refrigeration, but using boil-off gas to provide propulsion, power and water), however the architecture will evolve, with increasing power requirements to allow for zero boil-off (refrigeration), and eventually allow for cryogenic propellant production from water launched to the depot from Earth or carried from extraterrestrial sources using advanced propulsion and/or aero-braking. 
The amount of energy needed to launch mass from the moon to LEO or L- 1 is much less than that to launch from Earth, so it may eventually be economical to use lunar resources to make cryogenic propellants for use in cis-lunar space and Trans-Mars Injection (TMI). One potential approach would carry cryogenic propellant from production facilities on the moon to an ISCPD at L-1, Low Lunar Orbit (LLO) or LEO. In this scenario, cryogenic oxygen and hydrogen are made from ice found in cold, permanently shadowed areas near the moon's poles. A lunar Lander is refueled and launched from the moon's surface to low lunar orbit, with further propulsion to reach $\mathrm{L}-1$ or a trans-earth injection trajectory (TEI). From TEI, multiple pass aero-braking could gradually lower the perigee to reach LEO without an aerobrake shield (a technique previously used at Venus and Mars). In the distant future, a more advanced approach might produce small "vehicles" filled with water from lunar resources; launch them via propellantless rail-gun to reach $\mathrm{L}-1$ or $\mathrm{TEI}$, and then convert the water into cryogenic propellants to be stored in an ISCPD.

Human missions to Mars will use larger quantities of propellant, requiring significant growth in ISCPD propellant capacity. The payload sent to Mars may also include significant amounts of liquid hydrogen (e.g., $18,700 \mathrm{~kg}$ ), thus the payload itself may include an ISCPD for cryogen storage throughout the long journey, with continuing storage in orbit around Mars and on the surface. On Mars, hydrogen from Earth may be combined with carbon dioxide from the atmosphere to make cryogenic methane and oxygen propellants for return to Earth $\left(2 \mathrm{H}_{2}+\mathrm{CO}_{2}=>\mathrm{CH}_{4}+\mathrm{O}_{2}\right.$ via the Sabatier process and electrolysis), along with excess oxygen for breathing, and water and power from fuel cells $\left(\mathrm{O}_{2}+2 \mathrm{H}_{2}=>2 \mathrm{H}_{2} \mathrm{O}+\right.$ Power $)$. Such an In-Situ Propellant Production (ISPP) strategy may significantly reduce the mass launched from Earth and the cost of the associated Mars Exploration program, and this scenario influenced the ESAS selection of oxygen and methane propellants for lunar ascent, as a precursor to use for Mars ascent.

\section{CONFIGURATION AND SYSTEM TRADES}

ISCPD capabilities are expected to evolve over time, starting with relatively simple initial systems, and improving upon these as technologies mature and confidence grows. For example, an initial ISCPD configuration may use passive storage of modest quantities of propellant in LEO, to serve human lunar exploration systems, with growth to use active refrigeration and store very large quantities of propellant for human missions to Mars. To the extent practical, ISCPD systems should be designed for preplanned product improvement, with configurations allowing a wide range of applications. Initial ISCPD facilities may operate in a micro-gravity environment in LEO, with additional facilities emplaced later on the moon, at Earth-Moon or Earth-Sun libration points, and in lunar orbit. As the architecture evolves to include In-Situ Propellant Production, depots may also operate in a high gravity environment on the Moon, Mars, and the moons of Mars. Table 2 summarizes the expected order of priority for ISCPD applications and their different environments. 
Table 2. Order of priority for ISCPD applications and their different environments.

\begin{tabular}{|c|c|c|c|c|c|c|}
\hline $\begin{array}{l}\text { LOCATION } \\
\text { FACTORS }\end{array}$ & $\begin{array}{l}\text { Low Earth } \\
\text { Orbit } \\
\text { (LEO) }\end{array}$ & $\begin{array}{c}\text { Lunar Surface } \\
\text { (e.g., Polar) }\end{array}$ & $\begin{array}{l}\text { Lunar Orbit } \\
\text { (e.g., Polar) }\end{array}$ & $\begin{array}{c}\text { L-Point } \\
\text { (e.g. E-M L-1) }\end{array}$ & $\begin{array}{l}\text { Mars Orbit } \\
\text { (\& moons) }\end{array}$ & Mars Surface \\
\hline Prown & 1. & 2 & 20.8 & 2013 & 3 & 4 \\
\hline $\begin{array}{l}\text { Exposure } \\
\text { to Sunilight } \\
\text { (Boil-off \& } \\
\text { solar } \\
\text { power) }\end{array}$ & $\begin{array}{l}\sim 60 \% \text { of } \\
\text { the time }\end{array}$ & $\begin{array}{l}\text { Near } 100 \% \text { on } \\
\text { polar mountain } \\
\& 0 \% \text { in crater }\end{array}$ & $\begin{array}{l}-60-100 \% \text {, } \\
\text { bi-weekly } \\
\text { variation }\end{array}$ & $\begin{array}{l}\text { Near } 100 \% \\
\text { (occasional } 1.5 \\
\text { hr eclipse) }\end{array}$ & $\begin{array}{l}\text { Near } 45 \% \text { of } \\
\text { solar constant at } \\
\text { Earth }\end{array}$ & $\begin{array}{l}24 \mathrm{hr} \text { day; } \\
\text { dust-storms; Year- } \\
\text { long day \& night at } \\
\text { Pole }\end{array}$ \\
\hline secondrat & Eratore & 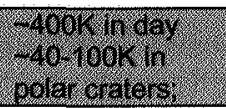 & 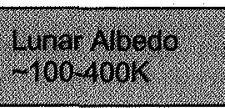 & Alortats & 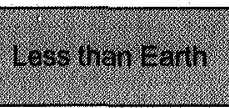 & a \\
\hline $\begin{array}{l}\text { Heat } \\
\text { Rejection }\end{array}$ & $\begin{array}{l}\text { Radiate to } \\
\text { deep } \\
\text { space }\end{array}$ & $\begin{array}{l}\text { Heat exchange } \\
\text { with lunar ice? }\end{array}$ & $\begin{array}{l}\text { Radiate to deep } \\
\text { space }\end{array}$ & $\begin{array}{l}\text { Radiate to deep } \\
\text { space }\end{array}$ & $\begin{array}{l}\text { Radiate to deep } \\
\text { space }\end{array}$ & $\begin{array}{l}\text { Dust issues; } \\
\text { Clouds }\end{array}$ \\
\hline 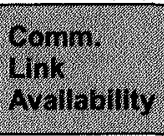 & 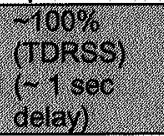 & 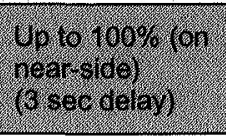 & 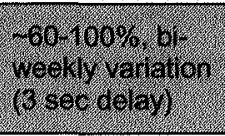 & 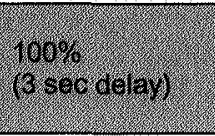 & 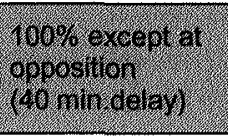 & 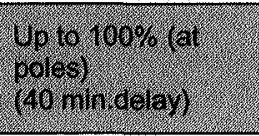 \\
\hline $\begin{array}{l}\text { Micro- } \\
\text { meteroid \& } \\
\text { Orbital } \\
\text { Debris }\end{array}$ & $\begin{array}{l}\text { No "up" } \\
\text { flux, gravity } \\
\text { increase } \\
\text { Debris } \\
\text { impacts } \\
\text { front \& } \\
\text { sides }\end{array}$ & $\begin{array}{l}\text { Large increase } \\
\text { from lunar } \\
\text { meteor ejecta } \\
\text { (top \& sides) }\end{array}$ & $\begin{array}{l}\text { No "up" flux, } \\
\text { gravity increase } \\
\text { Lunar ejecta } \\
\text { impacts front }\end{array}$ & $\begin{array}{l}\text { Natural deep } \\
\text { space flux } \\
\text { Orbital debris } \\
\text { absent }\end{array}$ & $\begin{array}{l}\text { Increased flux of } \\
\text { meteoroids } \\
\text { No orbital debris }\end{array}$ & $\begin{array}{l}\text { Protected by } \\
\text { atmosphere }\end{array}$ \\
\hline propingrom & 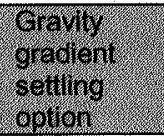 & $\cos x+169$ & 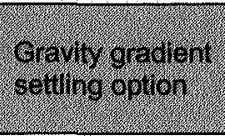 & No gravintred & straving gradent & Gravity = 10, \\
\hline
\end{tabular}

ISCPD tanks are expected to be quite large. We considered using extremely-large tanks, launched as a monolithic structure, as well as moderately-large tank modules, joined to other modules in space to create a depot. Small tanks were only considered briefly, as their mass is higher for a given quantity of propellant (due to a higher surface area to volume ratio), however small tanks may be needed for high pressure (supercritical) fluid. The main issue for larger tanks is access to orbit, and the favored design solutions are to launch ISCPD tanks as upper stages using only some of their cryogenic propellants to reach LEO, and continuing to store propellants in orbit. The ISCPD tanks were based on Delta Expendable Launch Vehicle (ELV) stages, but the same general logic could apply to other launch systems, including variants of the ESAS architecture.
It would be possible to place a very large ISCPD in orbit with a single launch. As is shown in Figure 3, a depot could be created with a capacity for 400 tons of cryogenic propellant by using Delta IV ELV "Common Booster Core" (CBC) tank-sets in both the launch vehicle and as the payload (replacing the fairing). During launch, propellant is transferred from the upper CBC task-set to the lower tank-set, and the engine burns longer with this added propellant, to place the entire monolithic structure into orbit. Such large tank-sets allow simple "gravity gradient" settling of their cryogenic propellants, as the related forces are much less than forces of surface tension in large tanks. [The "Bond number" is very large, $\mathrm{Bo}=$ Bond Number $=$ $(2 p a R) / \sigma$, where $a=$ acceleration, $\mathrm{R}=$ tank radius, $\rho=$ density, and $\sigma=$ surface tension]. Gravity gradient orientation, however, is undesirable for atmospheric 
drag and debris impact hazards, and other techniques tend to settle propellant to the same end of the depot (vs. opposite ends). The large monolithic depot would also require a single dedicated launch, adding a risk of losing the entire depot in a single failure, and it would arrive in LEO nearly empty.

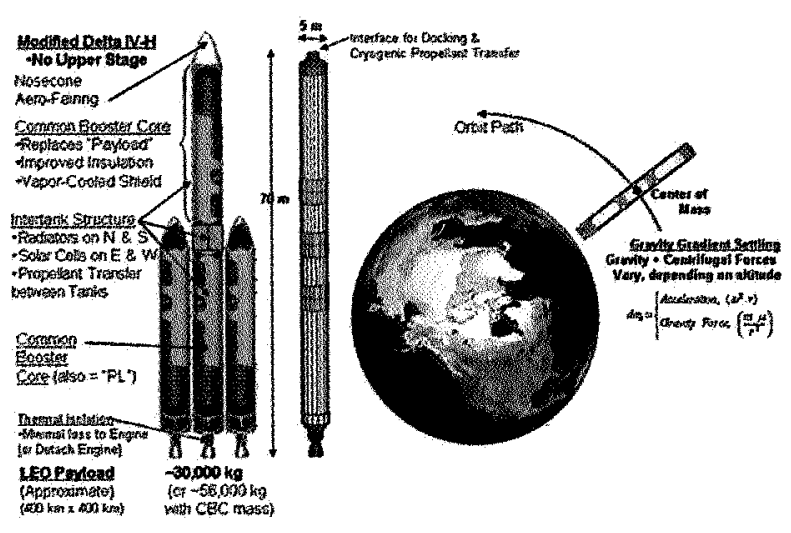

Figure 3. A large monolithic depot could reach LEO with a single launch with near-empty tanks.

More modestly sized depot tanks could reach LEO nearly full of propellants, requiring only a small propulsive maneuver for orbit circularization after release in a sub-orbital trajectory. Figure 4 illustrates such a depot tank-set launched in place of a cryogenic upper stage. In this scenario, a main engine, typically required for upper stages, is not needed, as lower thrust $\mathrm{H} 2-$ $\mathrm{O} 2$ thrusters are sufficient to perform a circularization burn over a long time interval at apogee. A single launch provides initial depot capabilities, including the delivery of propellants. The configuration can grow with the modular addition of more tank-sets, as well as additional power and thermal radiation systems for refrigeration and zero boil-off. The modular approach allows tailoring of depot propellant capacity to meet re-supply needs that change depending upon time and depot location with improved debris protection. While configuration details may vary, such a modular approach is recommended as the most practical course for gradual development of ISCPD capabilities.

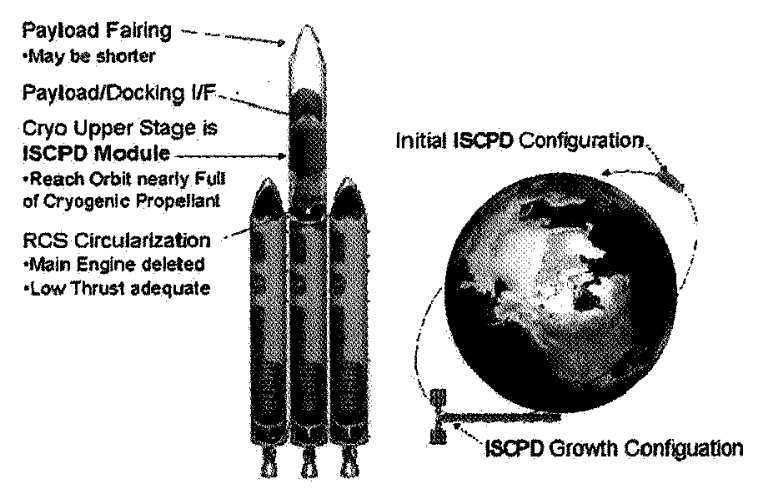

Figure 4. Modular depot tanks can launch as upper stages, reaching LEO nearly full.

A wide range of techniques could settle cryogenic propellants for acquisition and transfer in zero gravity. We expect ISCPD settling techniques to also evolve with time: initial settling could use boil-off gas from a receiving vehicle's hydrogen tank as a propellant to provide a low thrust. Techniques without propulsive thrust will be required when ISCPD capabilities grow to include "zero-vent fill" (with more power and refrigeration). Techniques include tank exchange, use of gravity gradient forces, surface tension, and system rotation or fluid rotation (in tanks). Of these, surface tension systems appear most promising as a baseline. Another advanced technique could use magnetic fields: since liquid oxygen is paramagnetic (attracted to a magnetic field) and liquid hydrogen is diamagnetic (repelled by a magnetic field) (note that the Earth's magnetic field may even need to be considered as an influence on propellant behavior in LEO).

\section{ALTERNATIVE CONCEPT DEFINITION AND ASSESSMENT}

Notional ISCPD system configurations were defined for comparison purposes and alternative conceptual designs also assessed. A reference depot module was defined, as summarized in Figure 5 . The module uses a thermodynamic vent system for hydrogen boil-off, with $\mathrm{H}_{2}$ gas passing through a vapor cooled shield on the tank 
wall, then conducting heat away from the oxygen tank before venting. A contingency vent system is included in the oxygen tank. The module shown in Figure 5 has a deployable multi-layer insulation blanket, which also provides protection for the hydrogen tank against micrometeoroids and orbital debris. Rigid insulation alternatives also have merit. Pressurization is autogenous, using small tanks of supercritical $\mathrm{H} 2$ and $\mathrm{O} 2$ gas, which also provide fuel cell reactants and RCS propellants. The module includes accommodations for autonomous docking and fluid transfer on both the forward and aft ends.

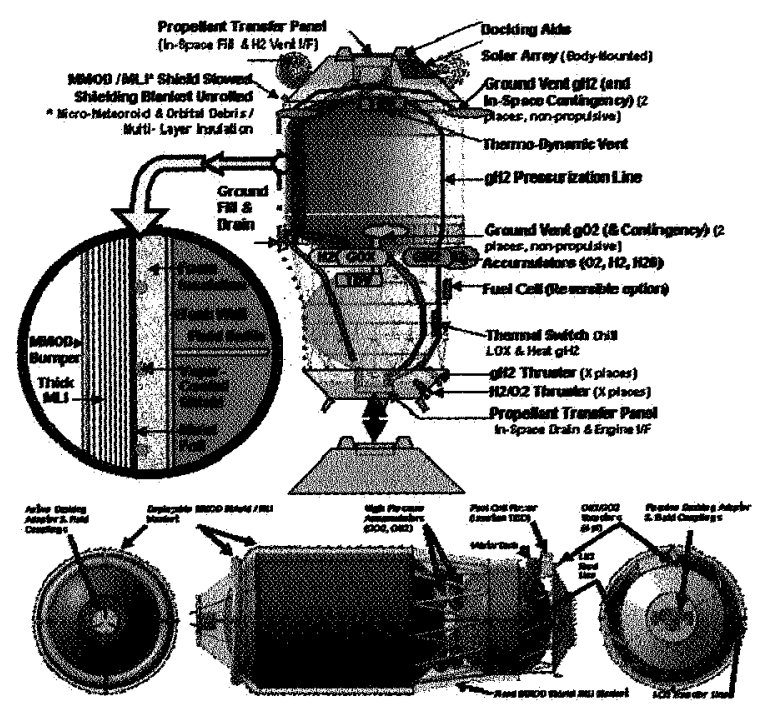

Figure 5. Reference ISCPD module concept.

Figure 6 illustrates growth of the ISCPD with additional modules and solar power. Solar power as shown, is based on existing satellite solar power systems, and is sized for a $20 \mathrm{kWe}$ peak power level (roughly 10 $\mathrm{kWe}$ average in LEO). In this view, one can see a preferred orientation with respect to the Earth. This orbital orientation minimizes drag, which tends to settle propellants forward, in the direction of the orbital velocity vector (equivalent to "downward" in the launch orientation). The low drag orientation exposes different parts of the module to different environments; LEO orbital debris hazards are most severe from the sides, meteoroids and sunlight come from above, and the Earth's heating (infrared and albedo) comes from below, thus modules surface details (insulation, thermal shielding, etc.) may be tailored to best meet these differing conditions.

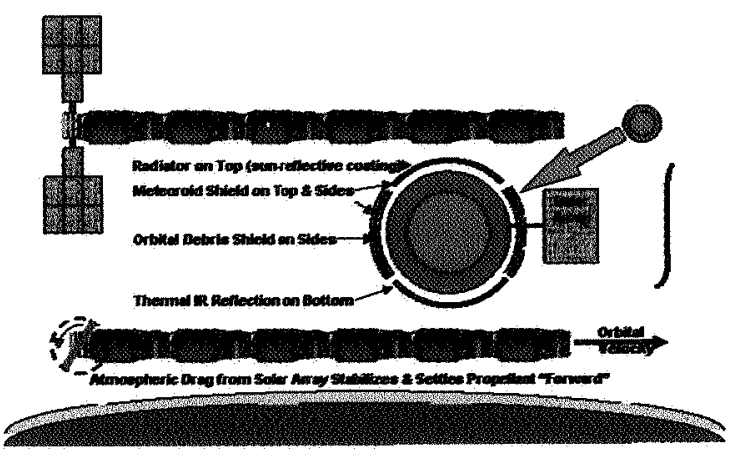

Figure 6. Growth ISCPD Facility in LEO: Add propellant and power for refrigeration.

Autogenous pressurization is important for the depot (and stages that it refuels) to avoid requirements for re-suppling high pressure helium gas, which is difficult to contain and transfer. Cryogenic liquid is transferred to a small "boiler tank" where it is warmed using thermal switches and heat exchangers to reach high pressure, becoming a supercritical fluid. This warmer fluid is then transferred to a Composite Overwrapped Pressure Vessel, and which in turn supplies $\mathrm{H} 2 / \mathrm{O} 2$ gas-gas Reaction Control System (RCS), fuel cells, and $\mathrm{H} 2$ low thrust propulsion systems as well as providing pressure for the cryogenic liquid tanks (to force fluid to transfer from the depot into lower pressure tanks on the receiving vehicle).

\section{TECHNOLOGY DEVELOPMENT PLANS}

Plans for development of critical ISCPD technologies include a potential space flight demonstration program and ground 
demonstration options that prepare for flight-testing. Cryogenic fluid management in zero- or micro-gravity has been analyzed extensively with few opportunities to verify analytical models in space. The ApolloSaturn 203 Flight was dedicated as an experiment to monitor cryogenic propellant conditions and dynamics in orbit; however this approach is fairly costly. Relevant space flight data can also be gained without significant cost, however, when flight experiments are performed as a secondary mission objective on a cryogenic upper stage, using its remaining cryogenic propellants after the primary payload is released. The Titan-Cenatur-2 Mission used this approach to perform two additional firings of the engine after storing cryogenic propellants for 1-hour and 3-hour coast intervals, and to demonstrate a "bubbler" system to reduce helium usage (by increasing the oxygen partial pressure). The Titan-Centaur-5 launch of Helios-2 also used this approach to demonstrate a total of seven burns of an RL-10 engine in a variety of conditions and storing cryogenic propellants for 5.25 hours between burns. Many future NASA launches could use a similar strategy to experiment with cryogenic propellants remaining in expended upper stages after their primary payloads are released. Typical cryogenic upper stage mission event sequences deploy the payload(s), then perform contamination and collision avoidance maneuvers (CCAM), including venting of remaining cryogenic fluids into space, as is illustrated in Figure 7.

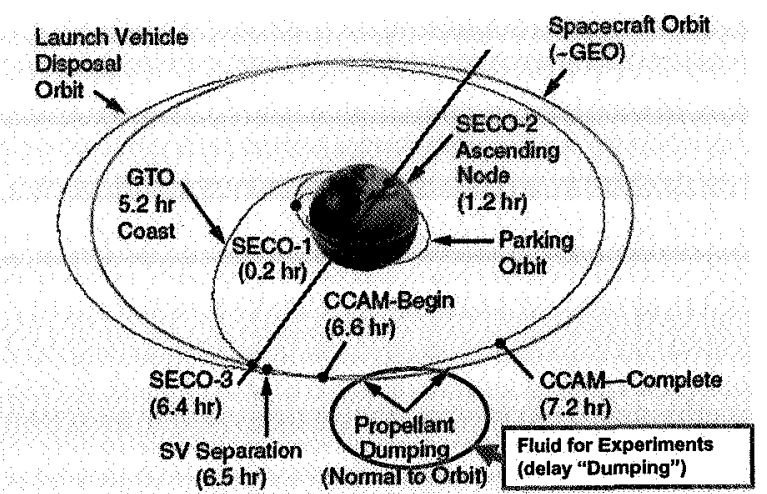

Figure 7. Cryogenic upper stages vent hundreds of pounds of remaining fluids that could be used for secondary flight experiments on virtually every mission.

After the spacecraft deployment occurs and the spacecraft reaches an acceptable distance from the Cryogenic Upper Stage, the stage reorients to a new position. The CCAM moves the stage away from the spacecraft orbit to prevent collision, and expels propellant (in a direction away from the spacecraft) to increase the separation distance and relative velocity, and to prevent subsequent tank rupture. Today's cryogenic upper stages typically complete their primary missions with significant masses of leftover fluids (hundreds of kilograms), including cryogenic liquids (residuals, reserves, trapped fluids, and a hydrogen bias), cold gas (hydrogen ullage gas, oxygen ullage gas, and residual helium), and even some hydrazine RCS propellant. 


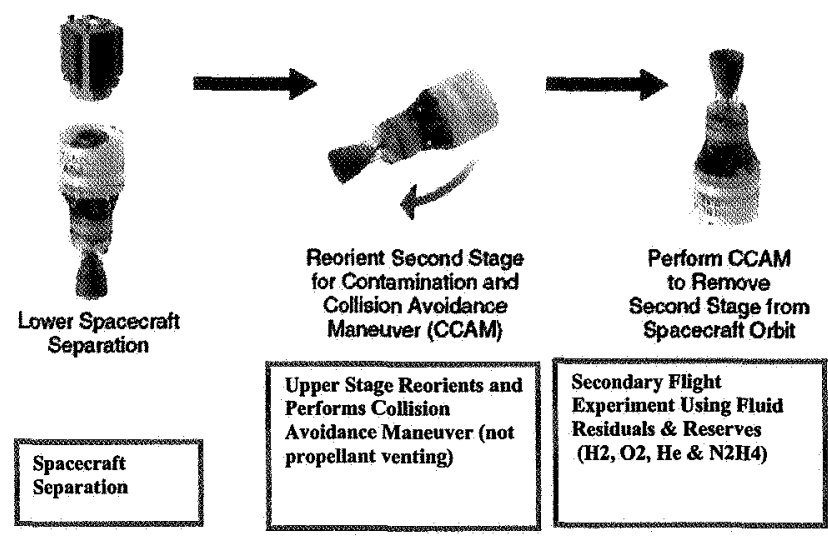

Figure 8. Secondary flight experiments on cryogenic upper stages may use residual propellants to test technology instead of dumping them shortly after payload separation.

As shown in Figure 8, simple flight experiments may test maneuvers or new hardware after the primary mission (e.g., to settle propellant or gauge its mass), and may use boiloff $\mathrm{H} 2$ for low-thrust, cold-gas propulsion. More complex flight experiments could use additional batteries or solar power (thermal or photovoltaic) to extend mission duration and could heat $\mathrm{H} 2$ boil-off gas to provide more efficient propulsion (specific impulse may reach 800 seconds in a resistojet or solar-thermal thruster, or higher with more advanced thrusters) or use $\mathrm{H} 2$ and $\mathrm{O} 2$ ullage gas for higher thrust chemical propulsion; either of these propulsion technologies might also be used on future missions before payload release, to significantly increase payload mass (adding hundreds of kilograms to the payload). Flight experiments on upper stages may also add hardware specific to ISCPD technology demonstrations; for example, selected lines on the upper stage may be tapped (with isolation valves closed until payload release) allowing transfer of leftover fluid into well-insulated cryogenic tanks and into high-pressure vessels for warm, super-critical storage (to be used as a pressurant, propellant, or fuel-cell reactant).

\section{CONCLUSIONS}

In-Space Cryogenic Propellant Depot systems offer significant advantages for NASA space exploration systems. Refueling of in-space transfer stages at an ISCPD can support NASA's ESAS lunar exploration architecture and may be enabling for human exploration of Mars. ISCPD sizing is expected to be moderate, allowing deliver of modules to LEO as upper stages without main engines, nearly full of propellant. ISCPD design recommendations include modular construction and features allowing autogenous pressurization (without helium gas). Technology demonstrations may use secondary experiments on cryogenic upper stages as a means for ready access to orbit.

\section{REFERENCES}

1 NASA ESAS Final Report: http://www.nasa.gov/pdf/140637main_ESA S_06.pdf

2 NASA Administrator's Speech at 52nd AAS Conference, 15 Nov. 2005: http://www.nasa.gov/pdf/138033main_griffin _aas1.pdf, pages 7-10

${ }^{3}$ Griffin B., Thomas B., Vaughan D., Drake, B., Johnson, L., and Woodcock, G., A Comparison of Transportation Systems for Human Missions to Mars, 40th Joint Propulsion Conference,11-14 July 2004, Fort Lauderdale, Florida, AIAA 2004-3834: http://www.inspacepropulsion.com/tech/pub s/AIAA2004 3834AComparisonofTransport ationSystemsforHumanMissionstoMars.pdf

${ }^{4}$ Weaver, D. B. and Duke, M. B., Mars Exploration Strategies: A Reference Program and Comparison of Alternative Architectures, AIAA-93-4212,

http://ares.jsc.nasa.gov/HumanExplore/Expl oration/EXLibrary/DOCS/EIC043.HTML

5 Zubrin R. M., Baker, D. A., and Gwynne, O., Mars Direct: A Simple, Robust, and Cost 
Effective Architecture for the Space Exploration Initiative, AIAA-91-0328, http://www.cbqc.net/mars/docs/md_reno.pdf

${ }^{6}$ Astronautix, Mars Exploration, http://www.astronautix.com/craftfam/martion s.htm

7 Turner, Andrew E., Low-cost launch and orbital depots: the Aquarius system, in The Space Review, January 30, 2006 http://www.thespacereview.com/article/544/ 1

8 Rice, E. E., Development of Lunar Ice/Hydrogen Recovery System Architecture, Final Report, NASA/NIAC Research Grant 07600-021, OTC-G083-FR2000-1, January 1, 2000; http://www.niac.usra.edu/files/studies/final_r eport/341Rice.pdf

9 Blair, B.B., Diaz, J., Duke, M. B., Lamassoure, E., Easter, R., Oderman, M., Vaucher, M., Space Resource Economic Analysis Toolkit: The Case for Commercial Lunar Ice Mining , Final Report to the NASA Exploration Team, December 20, 2002, http://www.mines.edu/research/srr/LDEM_D raft4-updated.pdf

${ }^{10}$ Sanders, G. ., In-Situ Resource Utilization (ISRU) Capabilities \& Roadmapping Activities, LEAG/SRR Meeting, Oct. 26, 2005, http://www.lpi.usra.edu/meetings/leag2005/ presentations/wed_am/01_sanders.pdf

11 Keaton, Paul W., A Moon Base/Mars Base Transportation Depot, Los Alamos National Laboratory Report LA-10552-MS, UC-34B, September 1985, http://www.physicsware.net/pdf/A_MM_Dep ot.pdf

12 Cordell, Bruce M., Transportation Approaches For Manned Mars Missions, AlAA Space Programs and Technologies Conference, September 25-28, 19901 Huntsville, AL, AIAA-1990-3892 http://www.aiaa.org/content.cfm?pageid $=40$ $6 \& g$ Table $=$ mtgpaper\&gID $=86562$

13 Kuck, David L., The Deimos Water Company, Space Manufacturing II, SSI, Princeton 8 May 1997; http://www.spacefuture.com/archive/the_dei mos_water_company.shtml

14 Jones, L. and Bagdigian, D., Space Station Propulsion: Advanced Development Testing of the Water Electrolysis Concept at MSFC, AIAA-89-2615, 25th Joint Propulsion Conference, Monterey, CA I July 10-12, 1989,

http://www.aiaa.org/content.cfm?pageid $=40$ $6 \& \mathrm{gTable}=$ mtgpaper $\& \mathrm{gID}=60854$

${ }^{15}$ Staff writers, NASA To Send New Oxygen Generating System To ISS, Space Daily, Feb 9, 2006 http://www.spacedaily.com/reports/NASA_T o_Send_New_Oxygen_Generating_System - To_ISS.html

${ }^{16}$ Bock, E. H. and Fisher, J. G., In-Space Propellant Processing Using Water Delivered as Shuttle Contingency Payload, AIAA-78-941, $14^{\text {th }}$ Joint Propulsion Conference, Las Vegas, NV, 25-27 July, 1978

17 Smitherman, D., Fikes, J., Roy, S., Henley, M., and Potter, S., Space Resource Requirements for Future In-Space Propellant Production Depots, Space Resources Utilization Roundtable III, October 24-26, 2001, http://www.mines.edu/research/srr/2001\%2 Opapers/SRURpaperfinal.pdf

${ }^{18}$ Hill, T., Orbital Supply Depots to Cut the Cost of Travelling to Low Earth Orbit and Beyond, International Space Development Conference, 2005, isdc.xisp.net/ kmiller/isdc_archive/ fileDownload.php/?link=fileSelect\&file_id $=18$ 3

19 Troutman, P., Orbital Aggregation \& Space Infrastructure Systems (OASIS) 
Executive Summary, 2 October, 2001, http://rasc.larc.nasa.gov/rasc_new/HP M/OASISEXEC_97.pdf

${ }^{20}$ Lo Martin W. and Ross, Shane D., The Lunar L1 Gateway: Portal to the Stars and Beyond, AIAA Space 2001 Conference, Albuquerque, New Mexico August 28-30, 2001,

http://www.cds.caltech.edu/ shane/papers/l o_ross_2001.pdf

${ }^{21}$ Keaton, P. ibid (see reference 8 )

${ }^{22}$ Garriott, O. and Griffin, M., Extending Human Presence into the Solar System, An Independent Study for The Planetary Society on Strategy for the Proposed U.S. Space Exploration Policy, July 2004, http://www.planetary.org/aimformars/studyreport.pdf

${ }^{23}$ Boeing, Space Solar Power and Platform Technologies for In-Space Propellant Depots, Final Report, Report Number RSS00HB656, Contract NAS8-99140, Mod.2, Task 3, November 14, 2000

${ }^{24}$ Marchetta, J., Winter, A., and Hochstein, J., Simulation and Prediction of Realistic Magnetic Positive Positioning for Space Based Fluid Management Systems,42nd AlAA Aerospace Sciences Meeting and Exhibit, Reno, Nevada, Jan. 5-8, 2004, AIAA-2004-1151, http://www. aiaa.org/content.cfm?pageid $=40$ $6 \& g$ Table=Paper\&gID $=13176$

25 Martin, J. and Holt, J., Magnetically Actuated Propellant Orientation, Controlling Fluids In A Low-Gravity Environment, 36th AIAAASME/SAE/ASEE Joint Propulsion Conference, 16-19 July 2000, Huntsville, Alabama, AIAA 2000-3440, http://www.aiaa.org/content. cfm?pageid $=40$ $6 \&$ gTable $=$ mtgpaper $\&$ gID $=5920$

26 Martin, J. and Holt, J., Magnetically Actuated Propellant Orientation, Controlling Fluids In A Low-Gravity Environment, 36th AIAA/ASME/SAE/ASEE Joint Propulsion
Conference, 16-19 July 2000, Huntsville, Alabama, AIAA 2000-3440, http://www.aiaa.org/content.cfm?pageid $=40$ $6 \& \mathrm{~g}$ Table $=$ mtgpaper\&gID $=5920$

${ }^{27}$ Chato, D.J., Marchetta, J., Hochstein, J.I. and Kassemi M., Approaches to Validation of Models for Low Gravity Fluid Behavior, NASA/TM-2005-213832,

http://gltrs.grc.nasa.gov/reports/2005/TM2005-213832.pdf

28 Plachta, D., and Kittel, P., An Updated Zero Boil-Off Cryogenic Propellant Storage Analysis Applied to Upper Stages or Depots in an LEO Environment

NASA/TM-2003-211691, June 2003, http://gittrs.grc.nasa.gov/reports/2003/TM2003-211691.pdf

29 Chato,D, Low Gravity Issues of Deep Space Refueling, January, 2005, AIAA2005-25186

http://www.aiaa.org/content. cfm?pageid $=40$ $6 \&$ T Table $=$ Paper $\& g l D=25186$

${ }^{30}$ NASA, Evaluation of AS-203 Low Gravity Orbital Experiment - Jan http://ntrs.nasa.gov/archive/nasa/casi.ntrs.n asa.gov/19680012073_1968012073.pdf

31 http://www.infothis.com/find/AS-203/

AS-203,

${ }^{32}$ R.F. Lacovic. Centaur Zero Gravity Coast and Engine Restart Demonstration on the Titan/Centaur (TC-2) Extended Mission, NASA TM X-71821, Oct. 1975, http://adsabs.harvard.edu/cgi-bin/nphbib_query?bibcode $=1975$ STIN...7613155L\& amp;db key=PHY\&amp;data type=HTML\& amp;format
${ }^{33}$ Henley, M. W., Secondary Applications of Expended Orbital Transfer Systems, October, 1989, IAF Congress- http://adsabs.harvard.edu/cgi-bin/nph- bib query?bibcode $=1989$ mala.iafcS....H\&a mp;db_key=PHY\&amp;data_type=HTML\&a $\mathrm{mp}$;format $=$ 


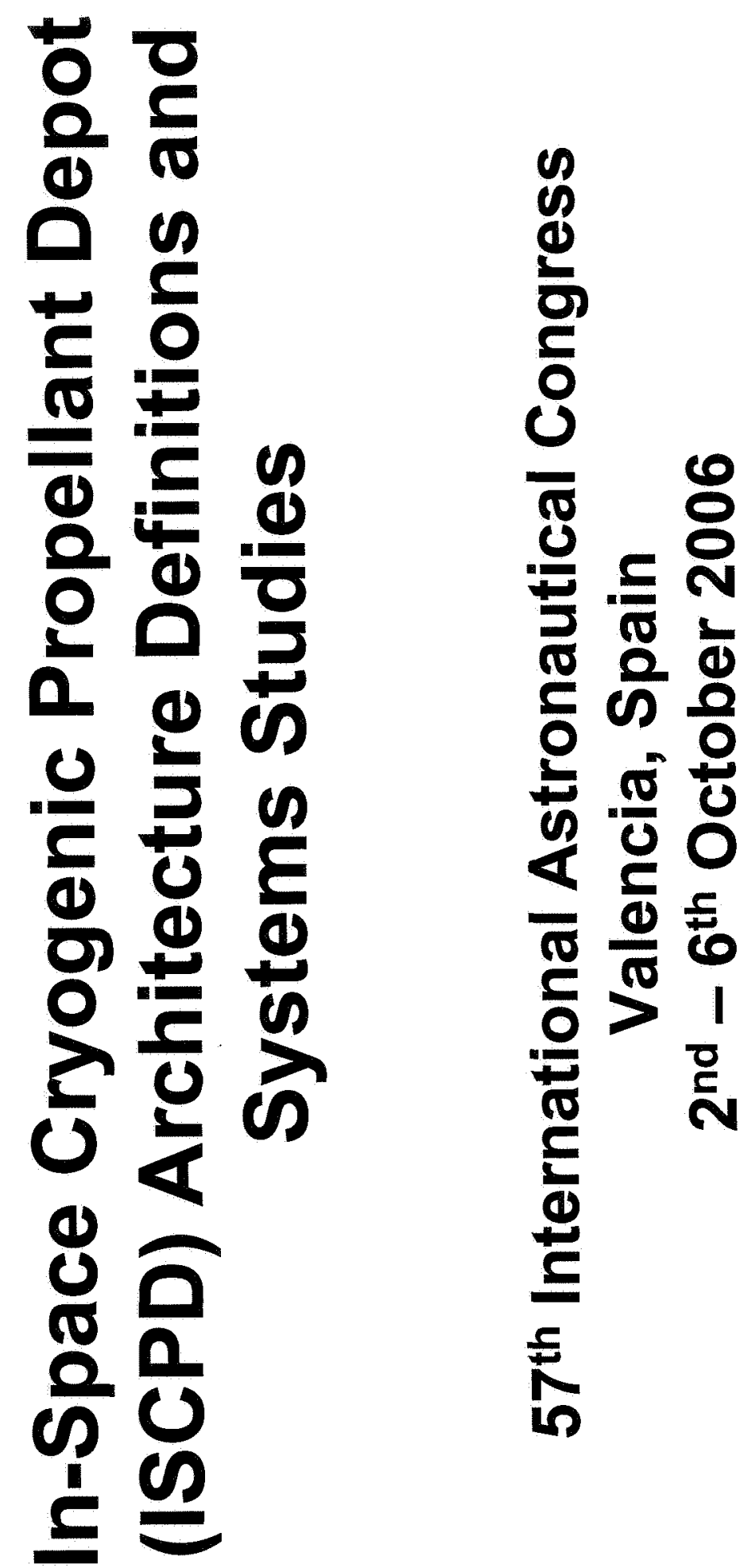



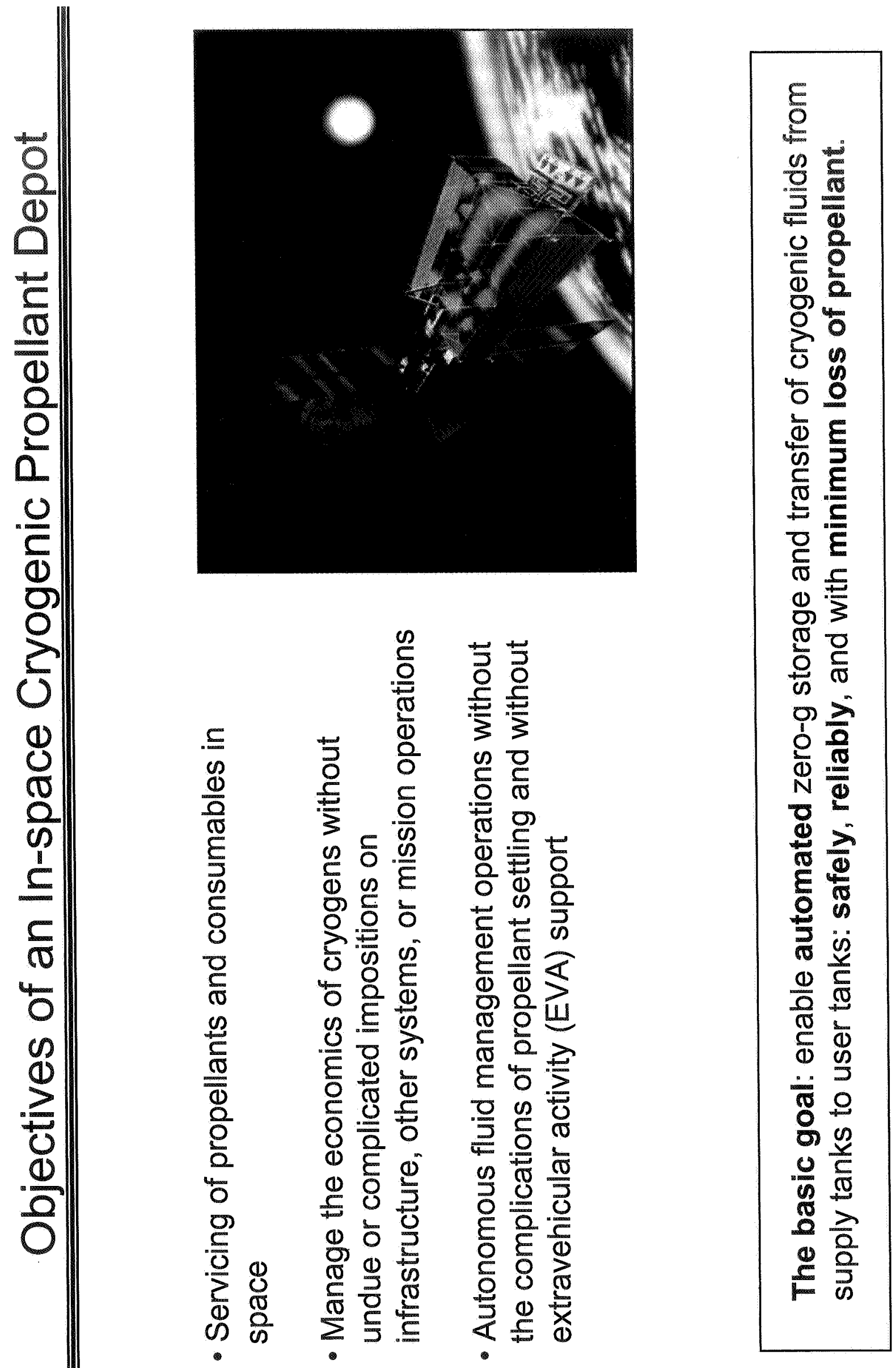


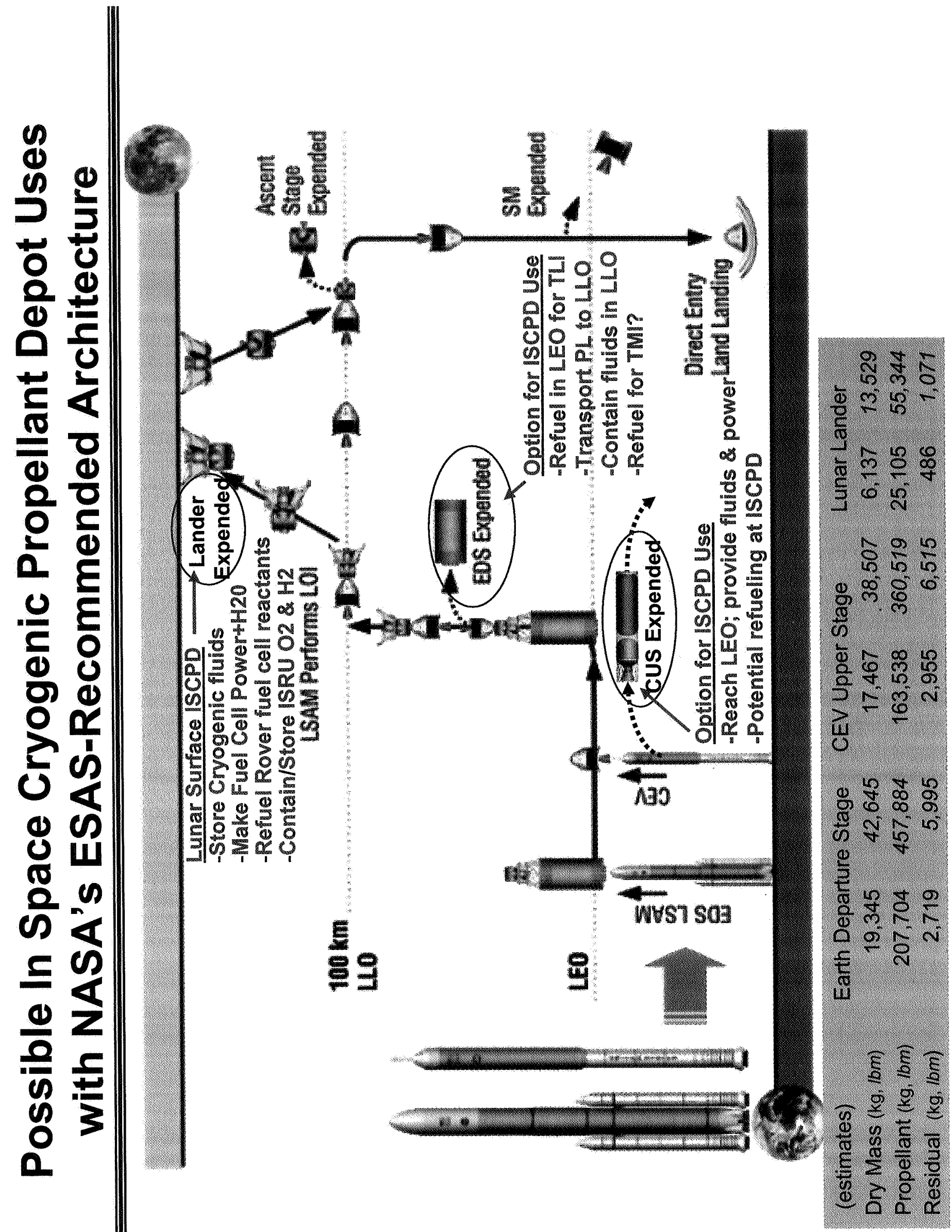




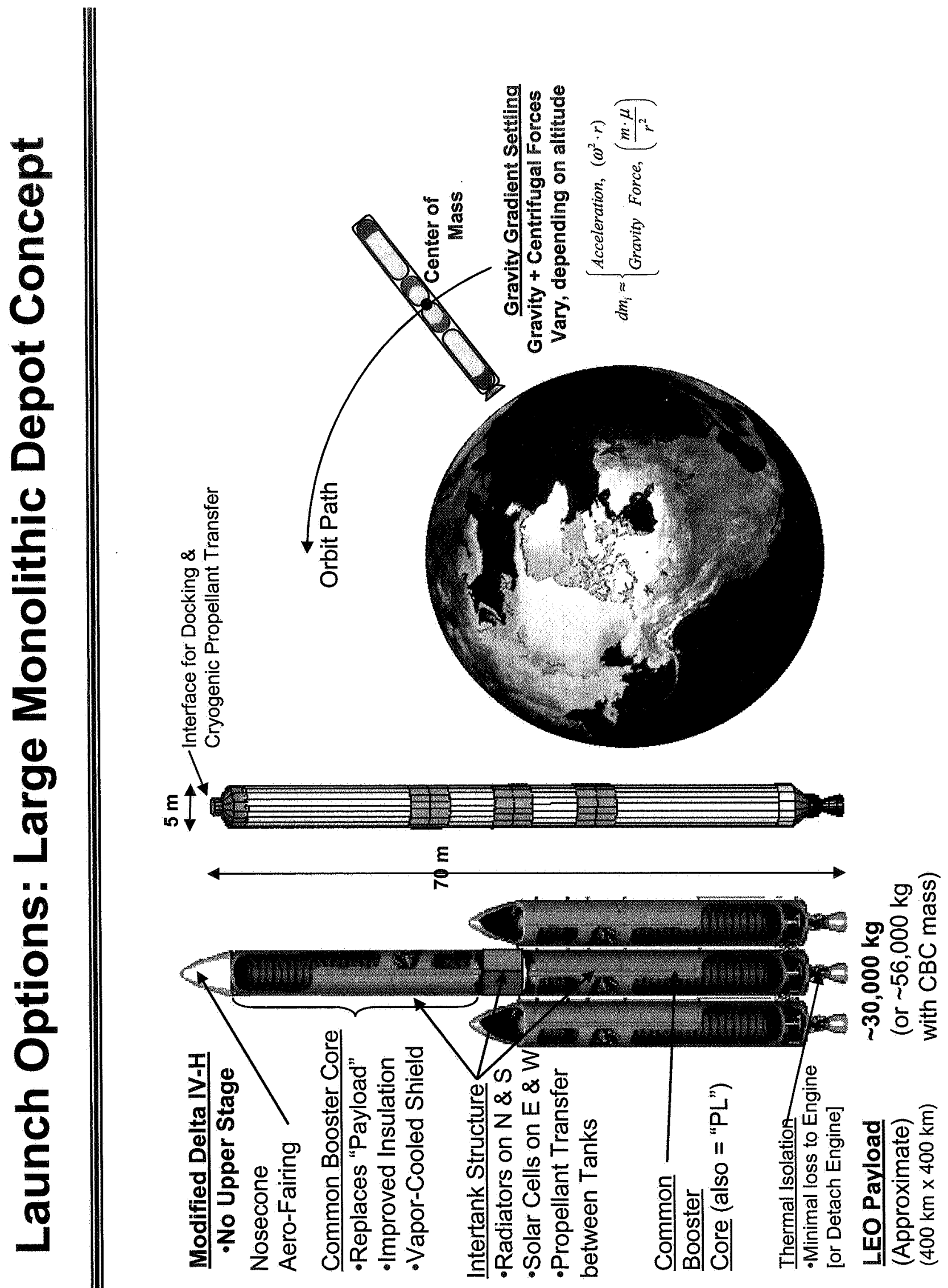




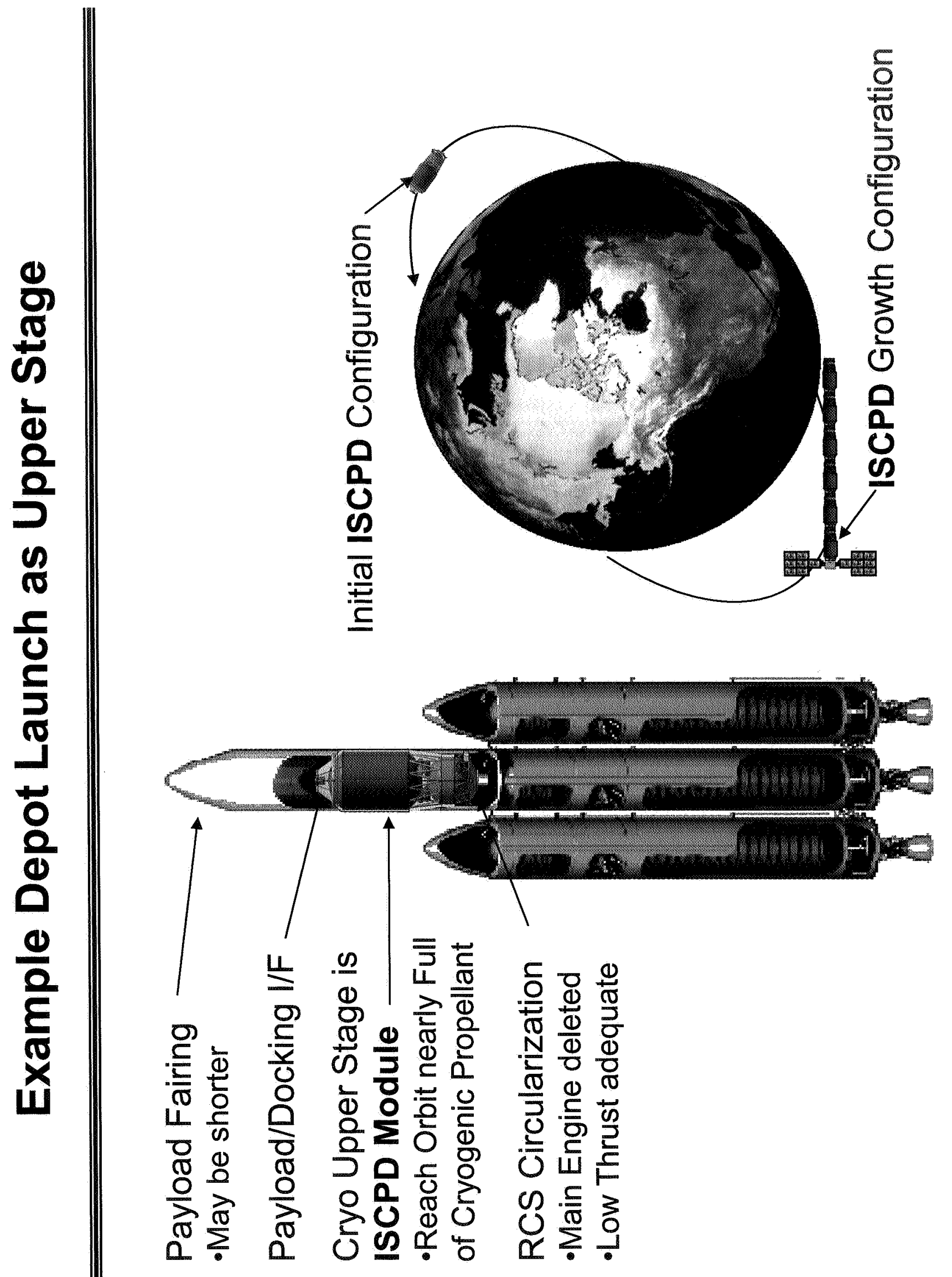




\begin{tabular}{|c|c|c|c|c|}
\hline 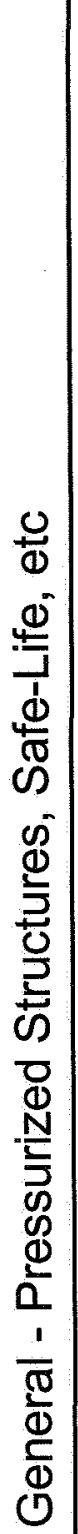 & 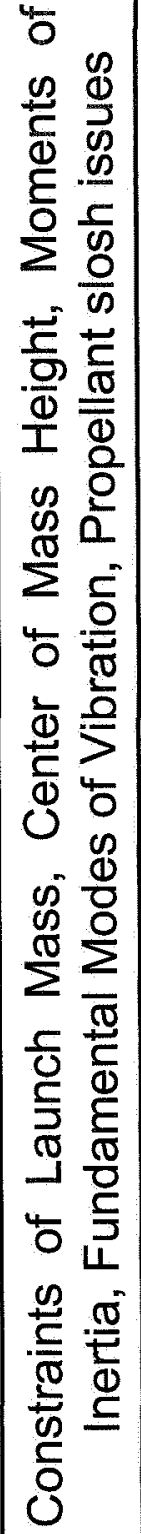 & 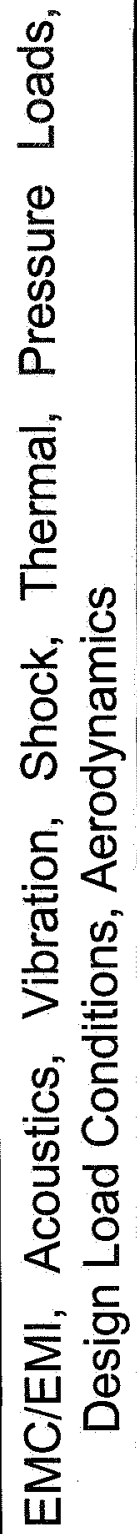 & 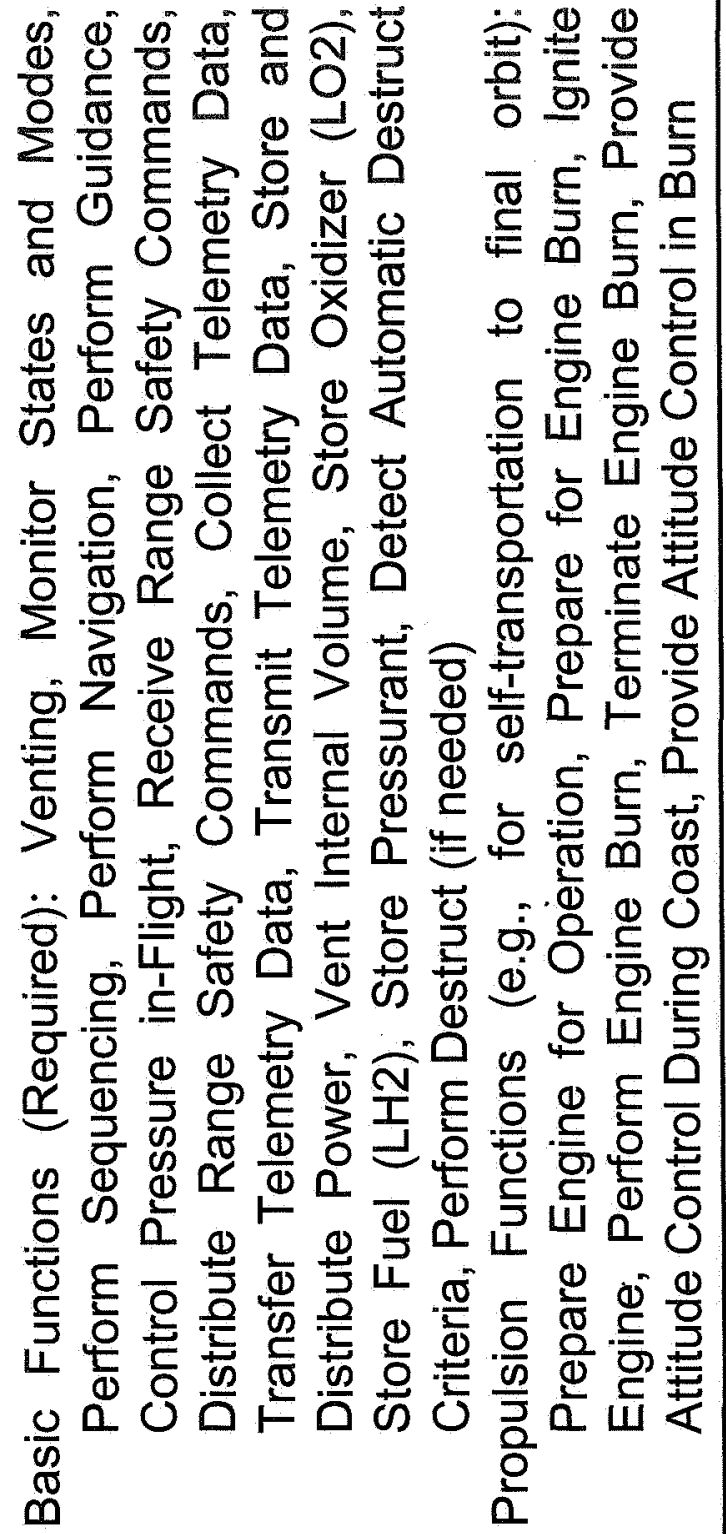 & 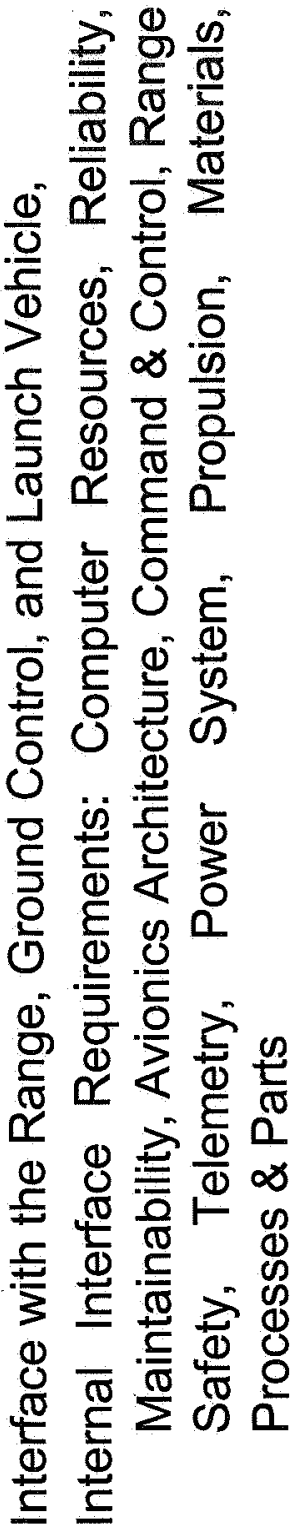 \\
\hline 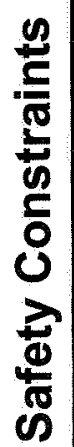 & 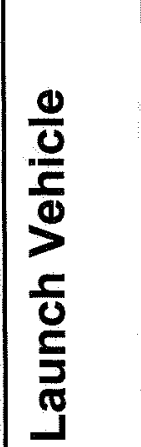 & 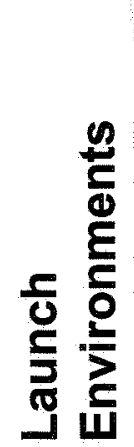 & 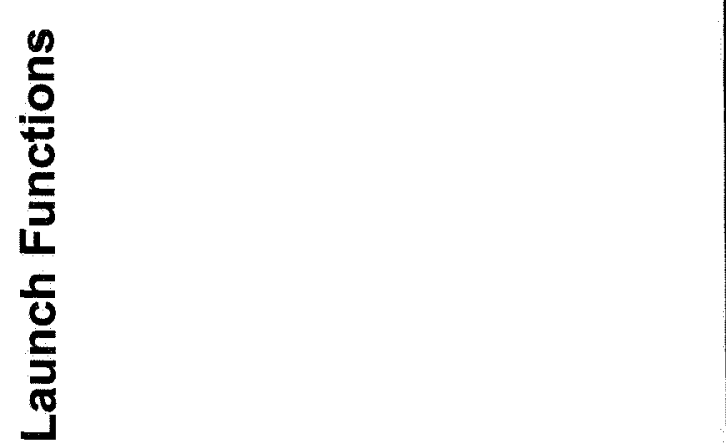 & 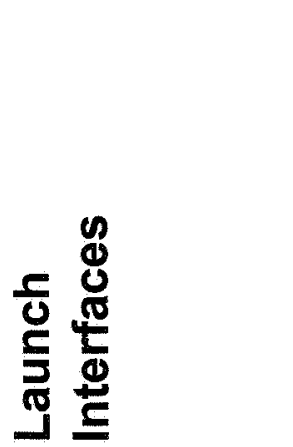 \\
\hline
\end{tabular}




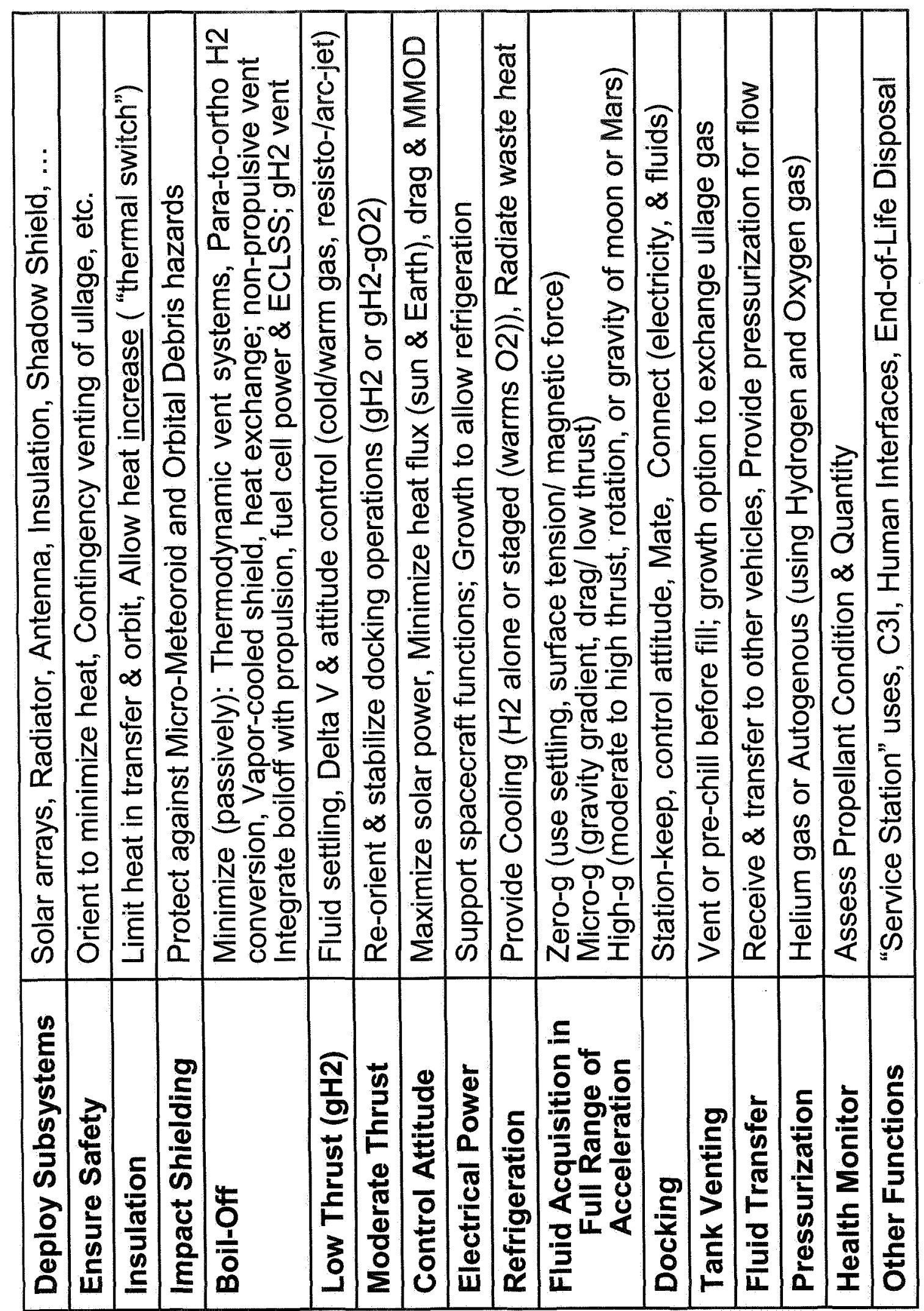




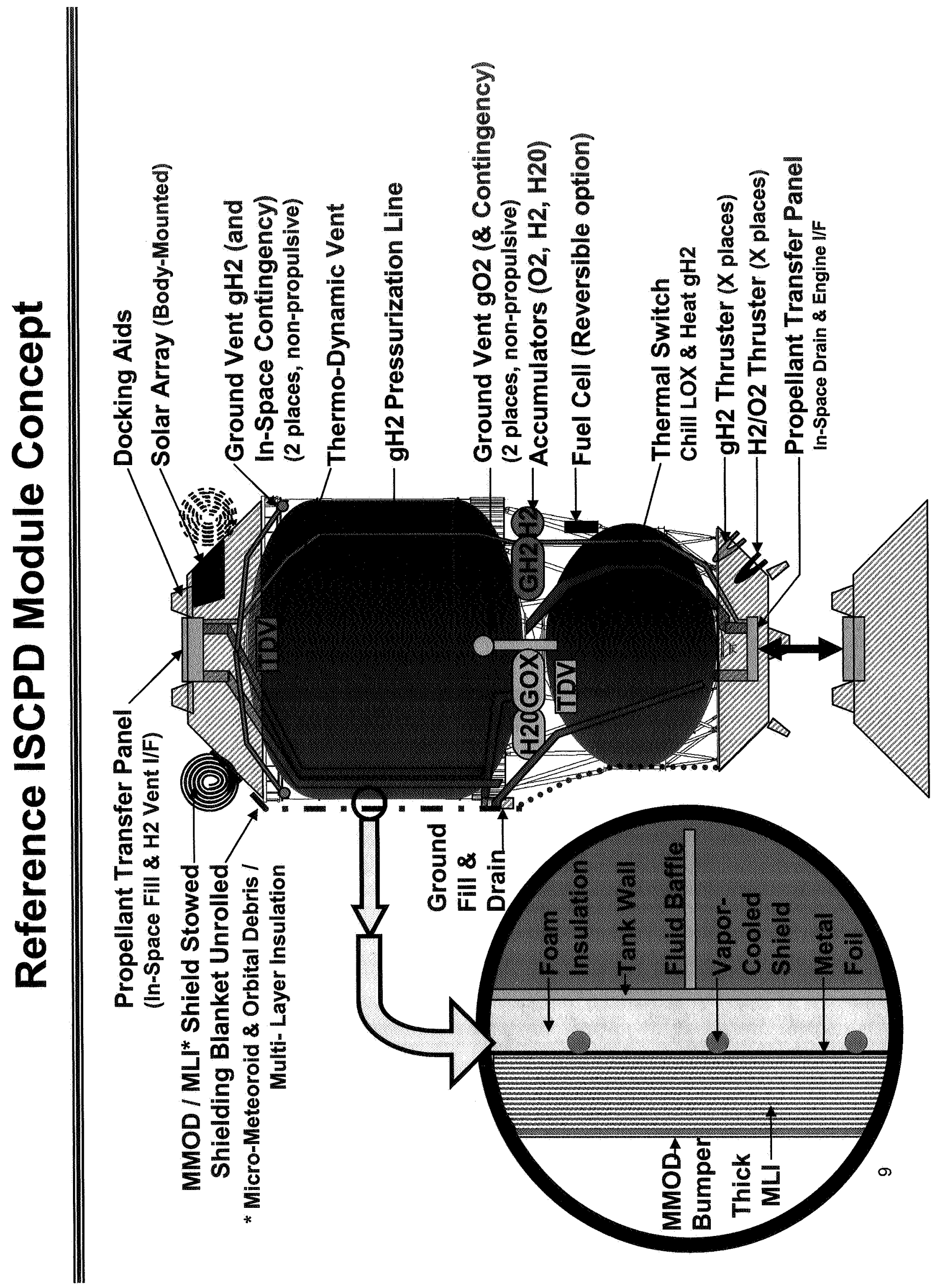




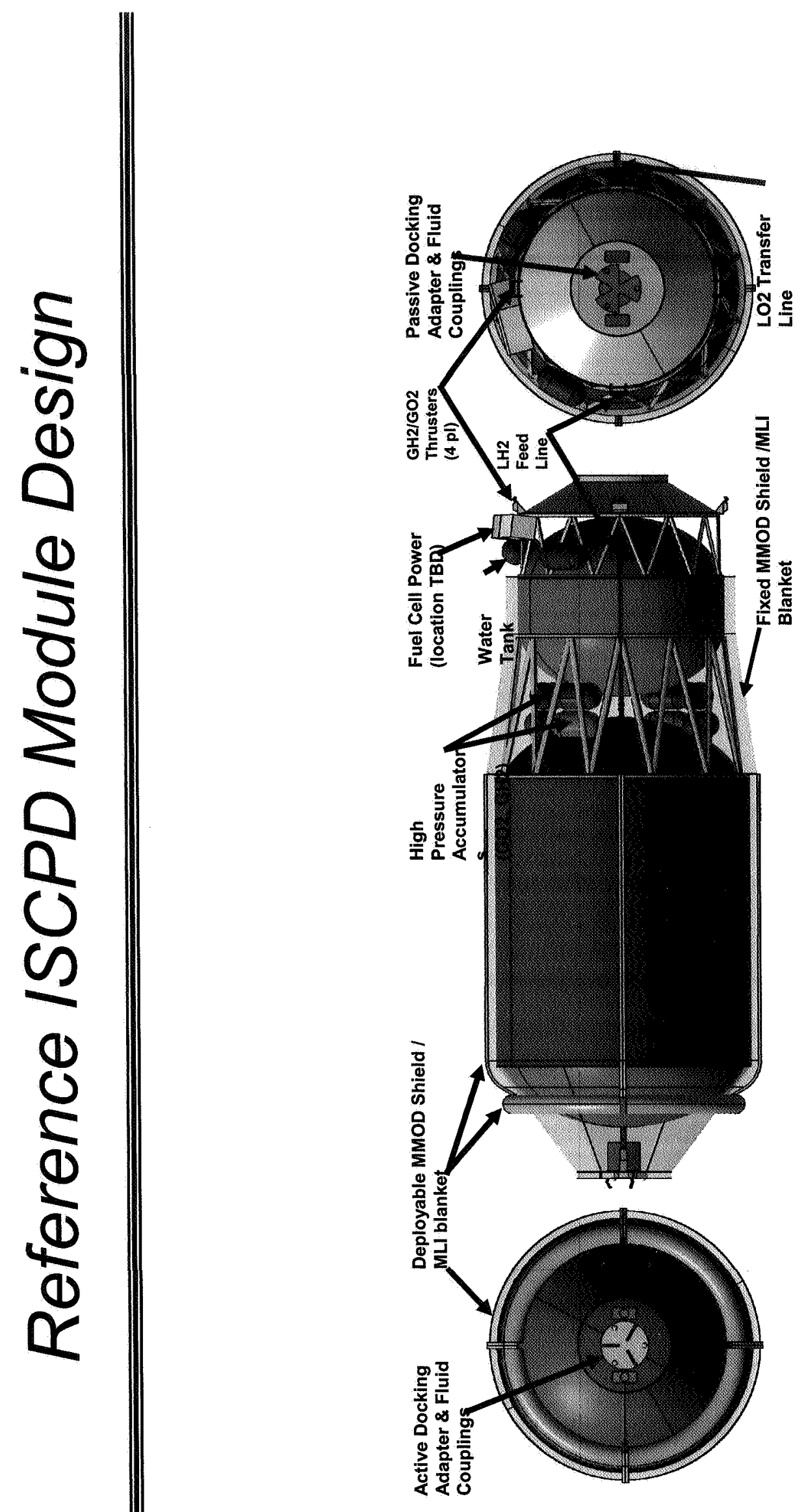




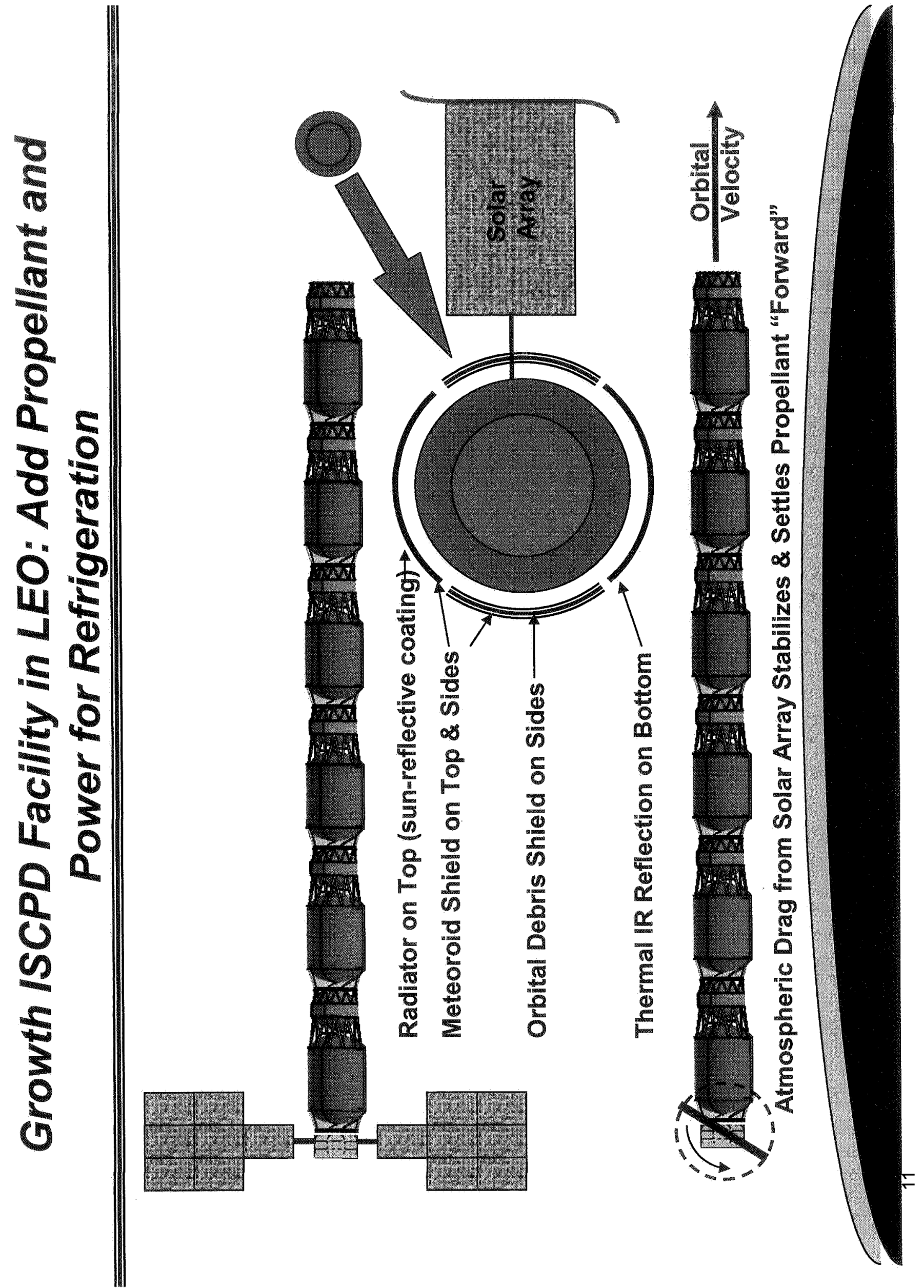




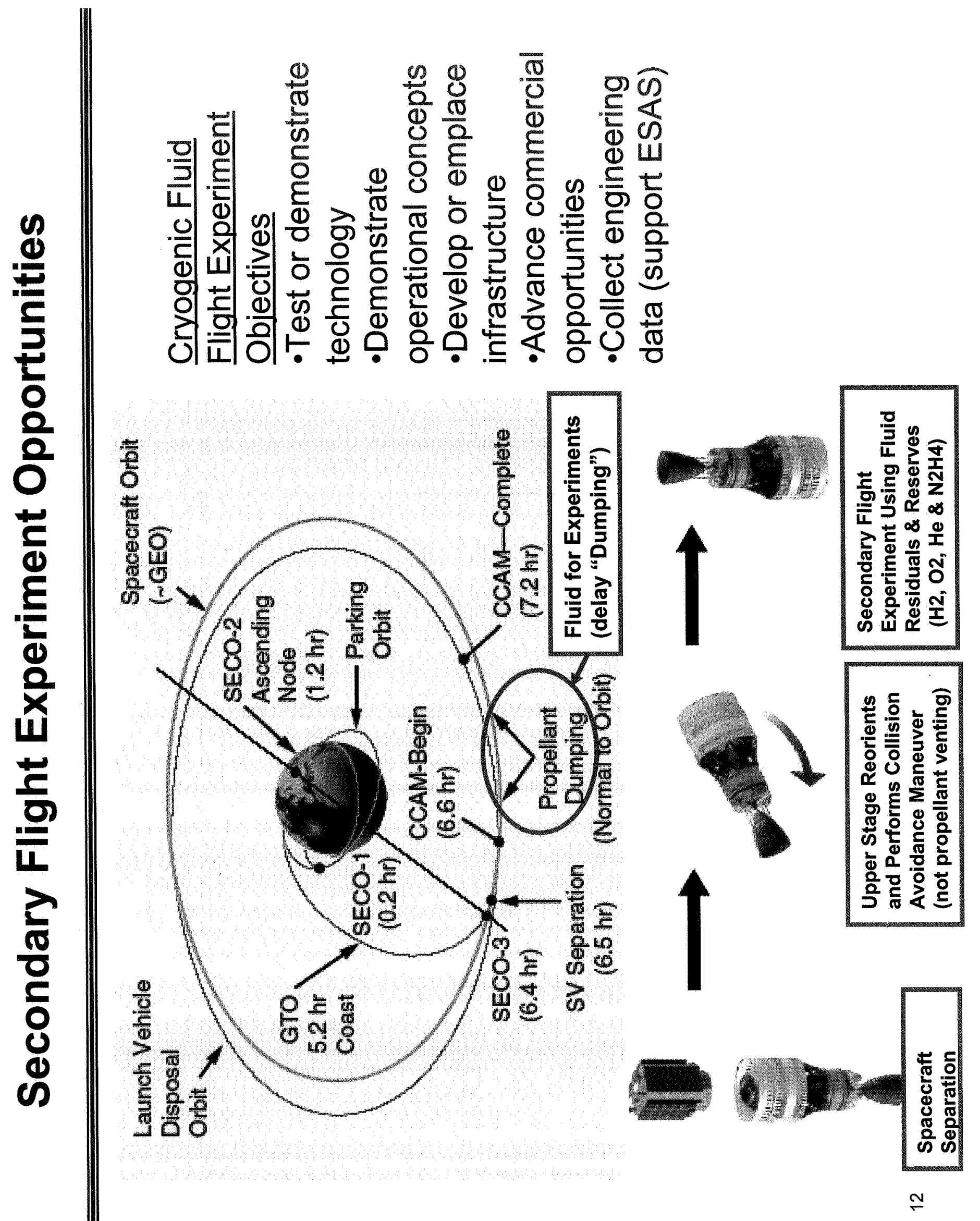




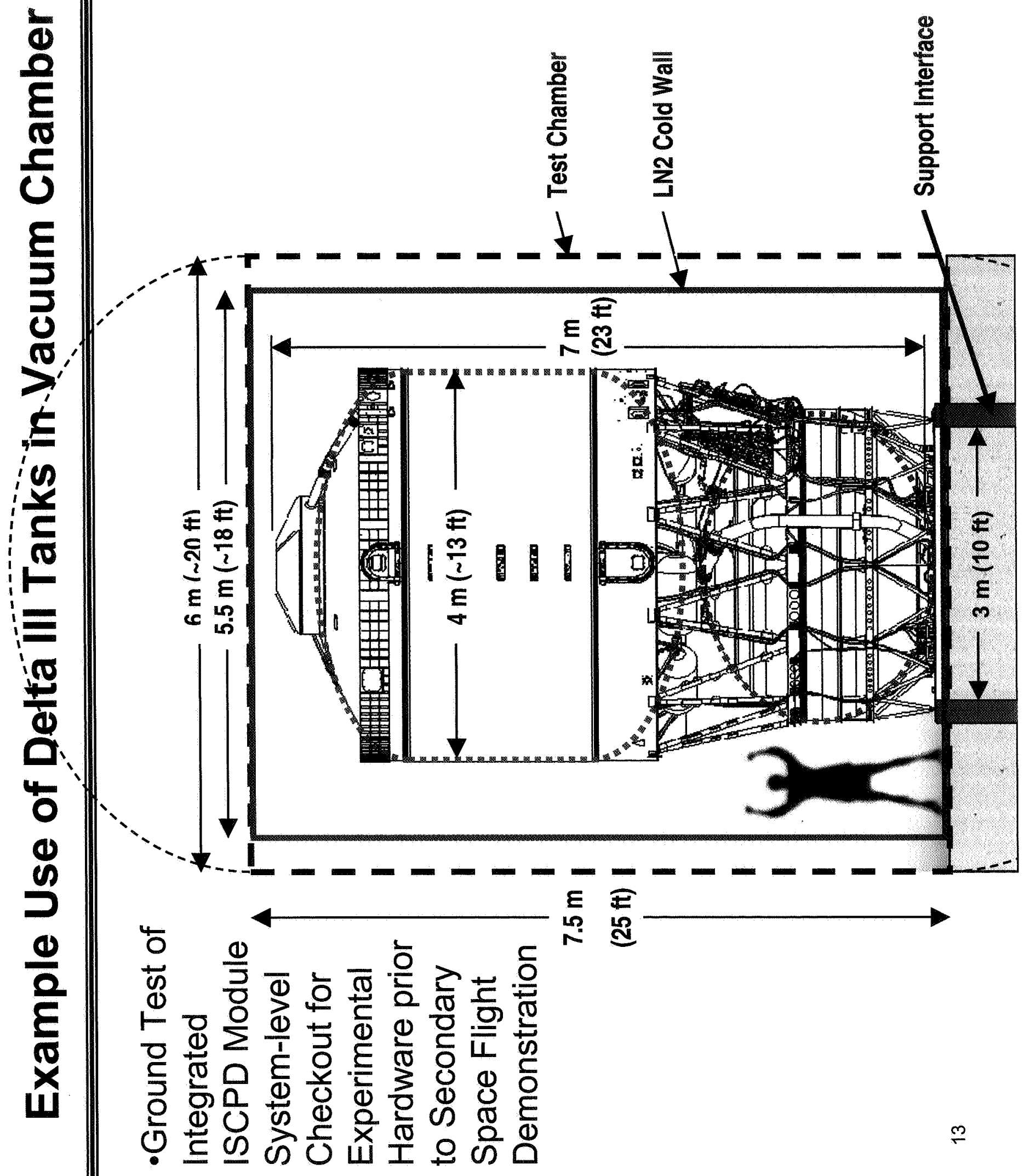




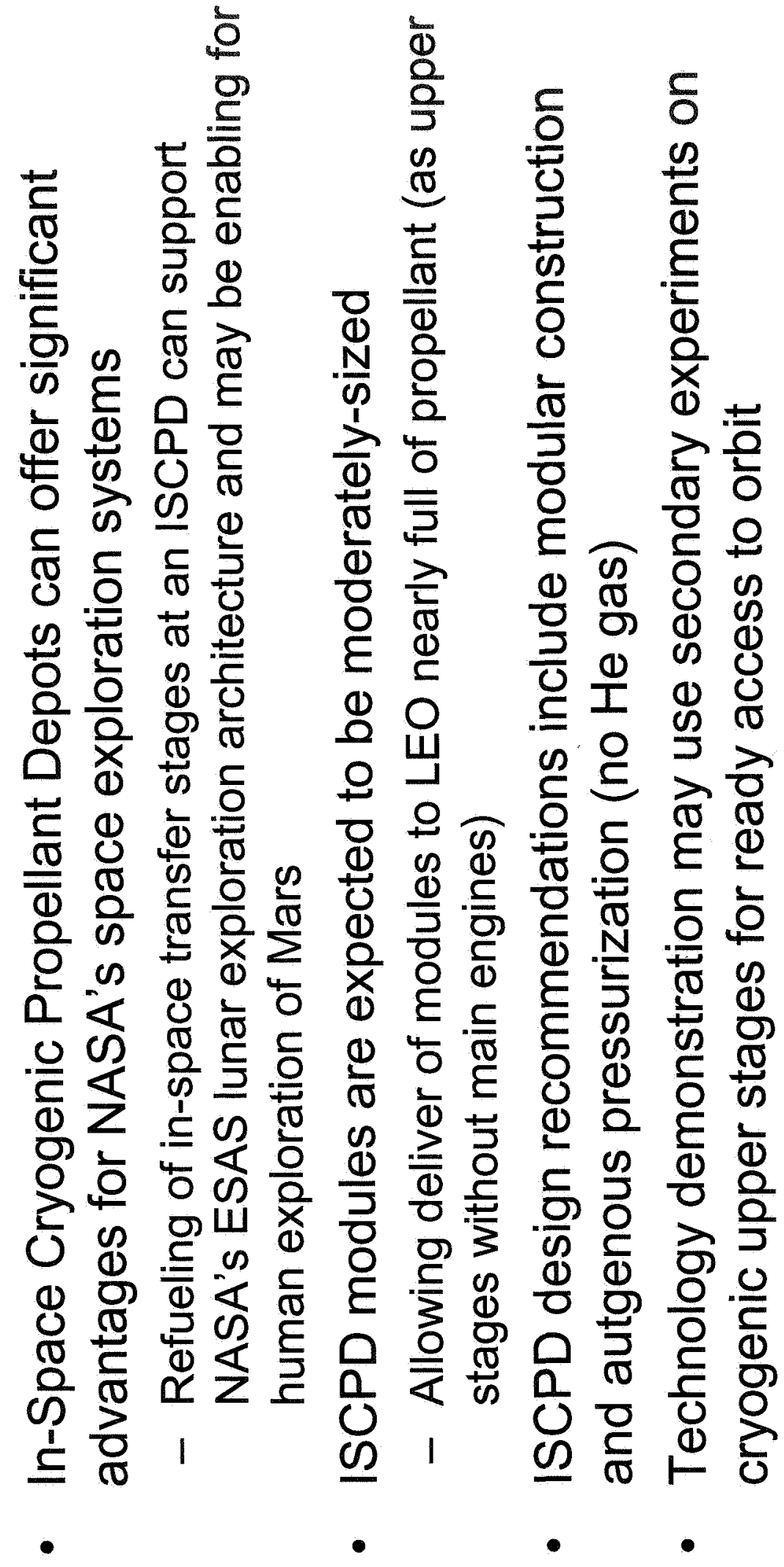

